\title{
EKSPERIMENTALNA APARATURA ZA SIMULACIJU SAGOREVANJA BIOMASE I KONTROLU AZOTNIH OKSIDA
}

\author{
EXPERIMENTAL APPARATUS FOR SIMULATION OF BIOMASS \\ COMBUSTION AND CONTROL OF NITROGEN OXIDE
}

\author{
Milica MLADENOVIĆ, Ana MARINKOVIĆ, Milijana PAPRIKA, Branislav REPIĆ, \\ Institut za nuklearne nauke Vinča, Laboratorija za termotehniku i energetiku, \\ Univerzitet u Beogradu, Beograd \\ mica@vinca.rs
}

\begin{abstract}
Iako se sagorevanje biomase promoviše sa stanovišta očuvanja životne sredine zbog značajno manje emisije štetnih gasova nego pri sagorevanju najzastupljenijeg domaćeg fosilnog goriva-uglja, eksperimenti sagorevanja više tipova biomase su pokazali da se i ovim sagorevanjem emituje izvesna količina polutanata koju je potrebno kontrolisati. Emisija azotnih oksida $\left(N O_{x}\right)$ je jedan od najvećih izazova u tom pogledu. Poznavanje i kontrolisanje emisije ovih oksida prilikom sagorevanja biomase je neophodno radi uspostavljanja korektnih zakonskih normi u pogledu granične emisije i za razvoj što kvalitetnijih tehnologija za sagorevanje ove vrste goriva. U tom cilju u radu je dat opis eksperimentalne aparature, koja ima za cilj da ispita efikasan način za redukciju NOx-a u dimnim gasovima upotrebom sekundarnih mera denitrifikacije. Takođe su dati i termički proračuni parametara sagorevanja u eksperimentalnom adijabatskom ložištu.

Ključne reči: biomasa, sagorevanje, emisija azotnih oksida

Even though biomass combustion is promoted from the standpoint of environmental protection due to significantly lower emissions in comparison to combustion of the predominate domestic fossil fuel-coal, combustion experiments with several types of biomass showed that the combustion emits a certain amount of pollutants which needs to be controlled. Emissions of nitrogen oxides (NOx) is one of the biggest challenges in this regard. Knowing and controlling the emissions of these oxides during the combustion of biomass is required for correct establishment of legal norms in terms of the emissions limits and to develop better technologies for combustion of these fuels. In that sense, the paper gives a description of the new experimental apparatus, which aims to explore an effective way to reduce NOx in the exhaust gas, using the secondary denitrification methods. The calculation of the main combustion parameters in the experimental adiabatic furnace are also given here.
\end{abstract}

Key words: biomass; combustion; emissions of nitrogen oxides

\section{UVOD}

Biomasa, kao i svako drugo gorivo, pri sagorevanju emituje izvesne polutante, od kojih su azotni oksidi posebno problematični. Njihov negativan efekat je višestruk i to pre svega u formiranju foto hemijskog smoga, prizemnog ozona, kiselih kiša, pogoršanja vidljivosti, oštećenja prirodnih ekosistema i useva, kao i zbog formiraju otrovnih i iritirajućih hemikalija u atmosferi koje uzrokuju respiratorne zdravstvene probleme. Među oksidima azota identifikovanim u atmosferi, azot monoksid (NO) i azot dioksid $\left(\mathrm{NO}_{2}\right)$ su najdominantniji zagađivači. Preko $90 \%$ oksida azota emitovanih u procesu sagorevanja čini $\mathrm{NO}$, dok ostatak čine $\mathrm{NO}_{2} \mathrm{i}_{2} \mathrm{O}$, pri čemu je $\mathrm{N}_{2} \mathrm{O}$ emitovan u procesima sagorevanja zanemarljiv u odnosu na $\mathrm{NO}$ i $\mathrm{NO}_{2}$. Uz to emisija $\mathrm{N}_{2} \mathrm{O}$ ne podleže zakonskim ograničenjima. NO se u atmosferi konvertuje $\mathrm{u} \mathrm{NO} \mathrm{NO}_{2}$ pa propisi iz oblasti zaštite životne sredine tretiraju sve okside azota kao $\mathrm{NO}_{2}$. Azotni oksidi se formiraju i iz atmosferskog azota $\mathrm{N}_{2}$, i od azota sadržanog u gorivu, sledećim mehanizmima:

- termički (Zeldovich) mehanizam - visoko temperaturska $\left(>1300^{\circ} \mathrm{C}\right)$ oksidacija atmosferskog azota kiseonikom iz vazduha za sagorevanje i

- promptni mehanizam - sagorevanje atmosferskog $\mathrm{N}_{2}$ i ugljovodonika u uslovima bogate smeše/veoma niskom odnosu vazduh-gorivo, i od azota sadržanog u gorivu mehanizmom

- oksidacije azota vezanog u gorivu - pri čemu nastaje tzv. gorivi NOx. 
Pri sagorevanju biomase oksidacija azota vezanog u gorivu je dominantan mehanizam formiranja NOx. Termički i promptni NOx je zanemarljiv zbog relativno niske temperature sagorevanja uslovljene niskom temperaturom topljenja pepela biomase [1-8].

\section{SAGOREVANJE BIOMASE I EMISIJA NOx}

Problemi vezani za emisiju NOx se mogu očekivati posebno pri sagorevanju poljoprivredne biomase. Razlog tome je što ova biomasa sadrži visok procenat azota kao posledicu izraženog sadržaja proteina zbog čega je ona i značajna kao nutrient. Pored toga upotreba azotnih đubriva u poljoprivredi dodatno doprinosi povećanju ovog elementa u biomasi [1]. Zastupljenost azota u sastavu različitih tipova biomase dat je u tabeli 1. iz koje se vidi da je azot zastupljeniji u poljoprivrednoj biomasi u odnosu na drvnu.

Tabela 1. Elementarna analiza tipičnih uzoraka biomase (\% masenih suvog goriva)

\begin{tabular}{|c|c|c|c|c|c|c|c|}
\hline \multicolumn{2}{|l|}{ Biomasa } & $\mathrm{C}$ & $\mathrm{H}$ & $\mathrm{N}$ & $\mathrm{S}$ & $\mathrm{O}$ & Ref. \\
\hline Drvna piljevina & & 46.9 & 5.2 & 0.1 & 0.04 & 37.8 & [9] \\
\hline Topola & & 48.4 & 5.9 & 0.4 & 0.01 & 39.6 & [9] \\
\hline Crvena hrastovina & & 50.0 & 6.0 & 0.3 & - & 42.4 & [9] \\
\hline Bukovina & & 49.5 & 6.2 & 0.4 & - & 41.2 & [9] \\
\hline Smreka & & 51.9 & 6.1 & 0.3 & - & 40.9 & [9] \\
\hline Ljuska lešnika & & 52.8 & 5.6 & 1.4 & 0.04 & 42.6 & {$[8]$} \\
\hline Koštica breskve & & 53 & 5.9 & 0.3 & 0.05 & 39.1 & [9] \\
\hline Maslinova komina & & 49.9 & 6.2 & 1.6 & 0.05 & 42 & [9] \\
\hline Ljuska badema & & 47.8 & 6 & 1.1 & 0.06 & 41.5 & [9] \\
\hline Ljuska oraha & & 53.5 & 6.6 & 1.5 & 0.1 & 45.4 & [9] \\
\hline Kukuruzna silaža & $\%$ & 42.5 & 5 & 0.8 & 0.2 & 42.6 & [9] \\
\hline Kukuruzni klip & & 49.0 & 5.4 & 0.5 & 0.2 & 44.5 & [9] \\
\hline Kukuruz u zrnu & & 43.7 & 7.2 & 1.2 & 0.01 & 45.7 & [1] \\
\hline Suncokretova ljuska & & 47.4 & 5.8 & 1.4 & 0.05 & 41.3 & [9] \\
\hline Pšenična slama & & 41.8 & 5.5 & 0.7 & - & 35.5 & [9] \\
\hline Pirinčana komina & & 47.8 & 5.1 & 0.1 & - & 38.9 & [9] \\
\hline Otpad od uzgoja čaja & & 48 & 5.5 & 0.5 & - & 44.0 & [9] \\
\hline Stabljika lucerke & & 45.4 & 5.8 & 2.1 & 0.09 & 36.5 & [9] \\
\hline Trava & & 46.7 & 5.9 & 0.8 & 0.19 & 37.4 & [9] \\
\hline Ostaci prerade šećerne trske & & 44.8 & 5.4 & 0.4 & 0.01 & 39.6 & [9] \\
\hline Ostaci prerade pamuka & & 42.8 & 5.4 & 1.4 & 0.5 & 35 & [9] \\
\hline
\end{tabular}

Emisija NO u slučaju sagorevanja 2 tipa biomase - kukuruza u zrnu a) i lešnikove ljuske b) data je na sl. 1 dijagramima a i b, respektivno. Na prikazanim dijagramima se jasno vidi da su izmerene visoke koncentracije NO u odnosu na druge gasove, iako je organizacija sagorevanja dobra, što je indukovano malom emisijom ugljen monoksida, povoljnim temperaturama sagorevanja i povoljnim viškom vazduha $[1,8]$.

Izmerene koncentracije NOx za date eksperimente sagorevanja, izračunate u odnosu na referentnu vrednost kiseonika u dimnim gasovima od $13 \%$ [10], su za kukuruz u zrnu $634 \mathrm{mg} / \mathrm{m}^{3}$, odnosno lešnikovu ljusku $329 \mathrm{mg} / \mathrm{m}^{3}$. Prema Uredbi o graničnim vrednostima emisija zagađujućih materija u vazduh [10], za postrojenja snage $100 \mathrm{~kW}$ do $1 \mathrm{MWth}$, granica je $250 \mathrm{mg} / \mathrm{m}^{3}$. Izmerena emisija ostalih gasova je bila daleko od zakonom propisanih limita.

Upravo ove navedene činjenice, kao i zastupljenost poljoprivredne biomase u ukupnom potencijalu biomase u Srbiji, bila je podsticaj da se detaljnije ispitaju mere denitrifikacije dimnih gasova pri sagorevanju poljoprivredne biomase. Kako pri sagorevanju biomase uticaj sadržaja azota u gorivu dominantno utiče na emisiju NOx [1], to primarne mere denitrifikacije - tehnike kontrole sagorevanja, same po sebi, često nisu dovoljne za zadovoljenje strogih granica emisije $\mathrm{i} / \mathrm{ili}$ su neprimenljive u pos- 
tojećim ložištima. Potrebna redukcija azotnih oksida se postiže primenom efikasnijih sekundarnih mera, a za biomasu agrarnog porekla, bogatu azotom, to je neophodna mera denitrifikacije. U ovoj fazi ispitivanja, razmatraće se selektivna nekatalitička redukcija kao jedna od najdominantnijih sekundarnih mera denitrifikacije.

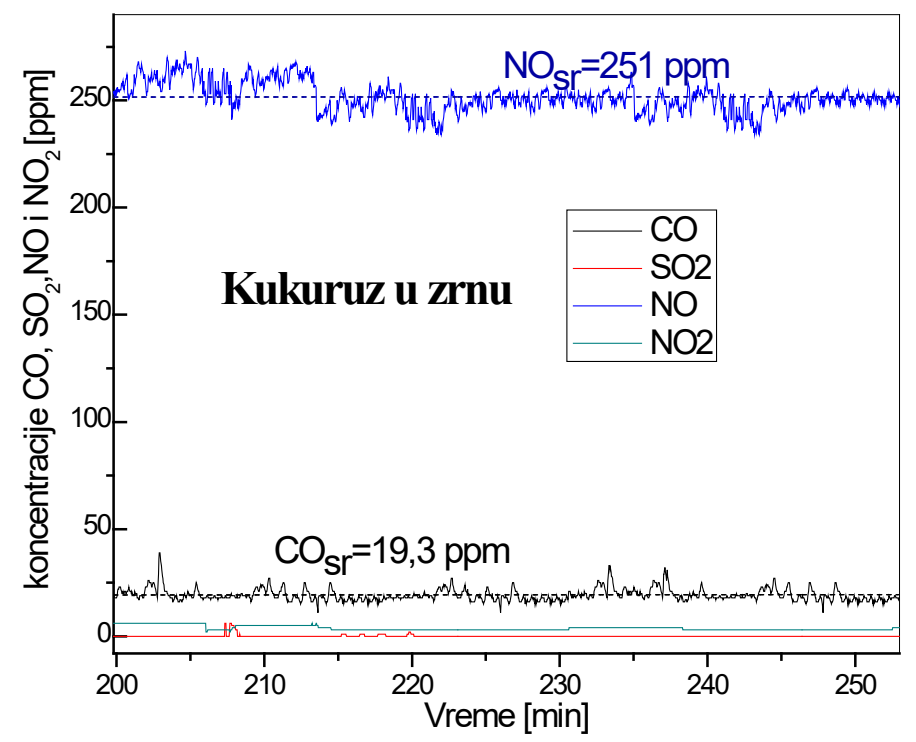

a) [1]

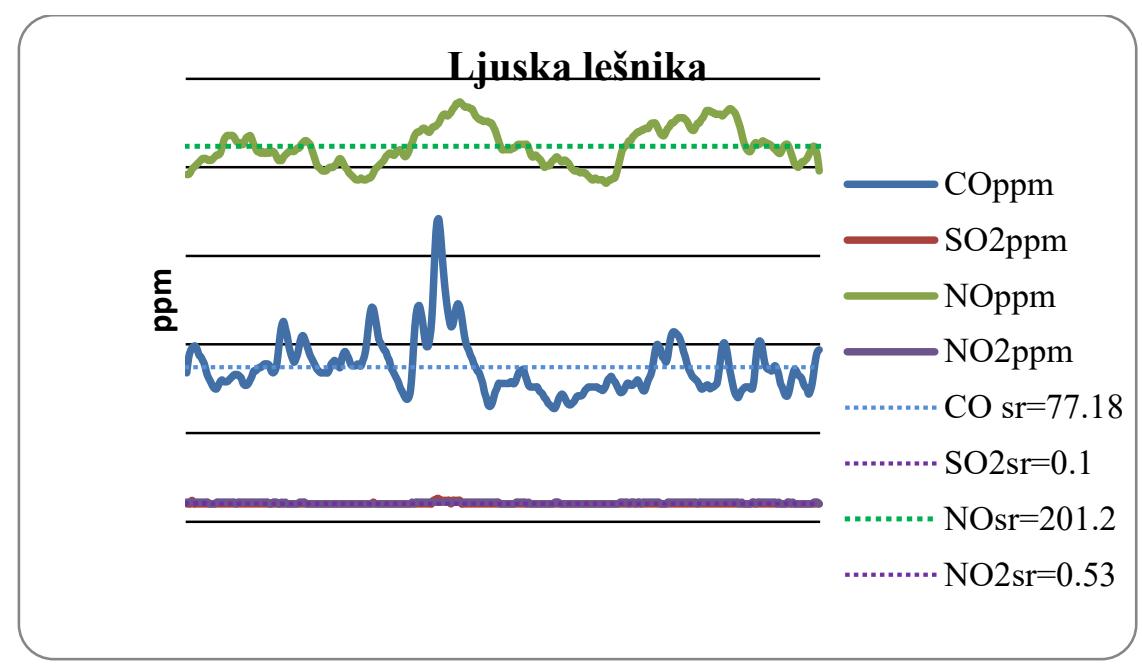

b) [8]

Slika 1. Emisija azot monoksida u slučaju sagorevanja 2 tipa biomase-kukuruza u zrnu a) i lešnikove ljuske b)

Selektivna nekatalitička redukcija (SNCR) je redukcija NOx na azot, $\mathrm{N}_{2}$, u prisustvu kiseonika, $\mathrm{O}_{2}$, u reakcijama sa reagensima na amino-bazi, bilo amonijakom $\left(\mathrm{NH}_{3}\right)$ ili ureom $\left(\mathrm{CO}\left(\mathrm{NH}_{2}\right)_{2}\right)$ na temperaturama od $800-1100^{\circ} \mathrm{C}$ (sl. 2), sa većom temperaturom potrebnom za ureu. Iako reagens može reagovati sa brojnim dimnim komponentama, reakcija redukcije NOx ima prednost nad drugim hemijskih reakcijama za određen temperaturski opseg i u prisustvu $\mathrm{O}_{2}$; stoga je to selektivan hemijski proces [7]. Dominantne reakcije su [7]:

U slučaju amonijaka kao reagensa:

$4 \mathrm{NO}+4 \mathrm{NH}_{3}+\mathrm{O}_{2} \rightarrow 4 \mathrm{~N}_{2}+6 \mathrm{H}_{2} \mathrm{O}(\mathrm{i})$

$6 \mathrm{NO}+4 \mathrm{NH}_{3} \rightarrow 5 \mathrm{~N}_{2}+6 \mathrm{H}_{2} \mathrm{O}$ (ii)

$6 \mathrm{NO}_{2}+8 \mathrm{NH}_{3} \rightarrow 7 \mathrm{~N}_{2}+12 \mathrm{H}_{2} \mathrm{O}$ (iii)
U slučaju uree kao reagensa:

$\left(\mathrm{CO}\left(\mathrm{NH}_{2}\right)_{2}\right)+2 \mathrm{NO}+1 / 2 \mathrm{O}_{2} \rightarrow 2 \mathrm{~N}_{2}+\mathrm{CO}_{2}+\mathrm{H}_{2} \mathrm{O}$ 


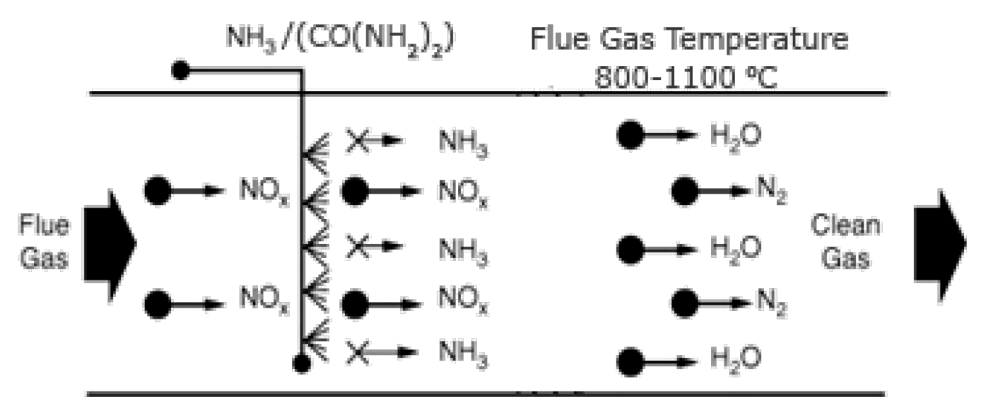

Slika 2. Šema selektivne nekatalitičke redukcije

\section{OPIS EKSPERIMENTALNOG ADIJABATSKOG LOŽIŠTA ZA SIMULACIJU SAGOREVANJA BIOMASE}

Radi što boljeg upoznavanja mehanizma selektivne katalitičke redukcije, jedne od najzastupljenijih mera sekundarne denitrifikacije, osmišljeno je adijabatsko ložište za simulaciju sagorevanja biomase, sa pratećom mernom i akvizicionom opremom koje je dato na slici 3.

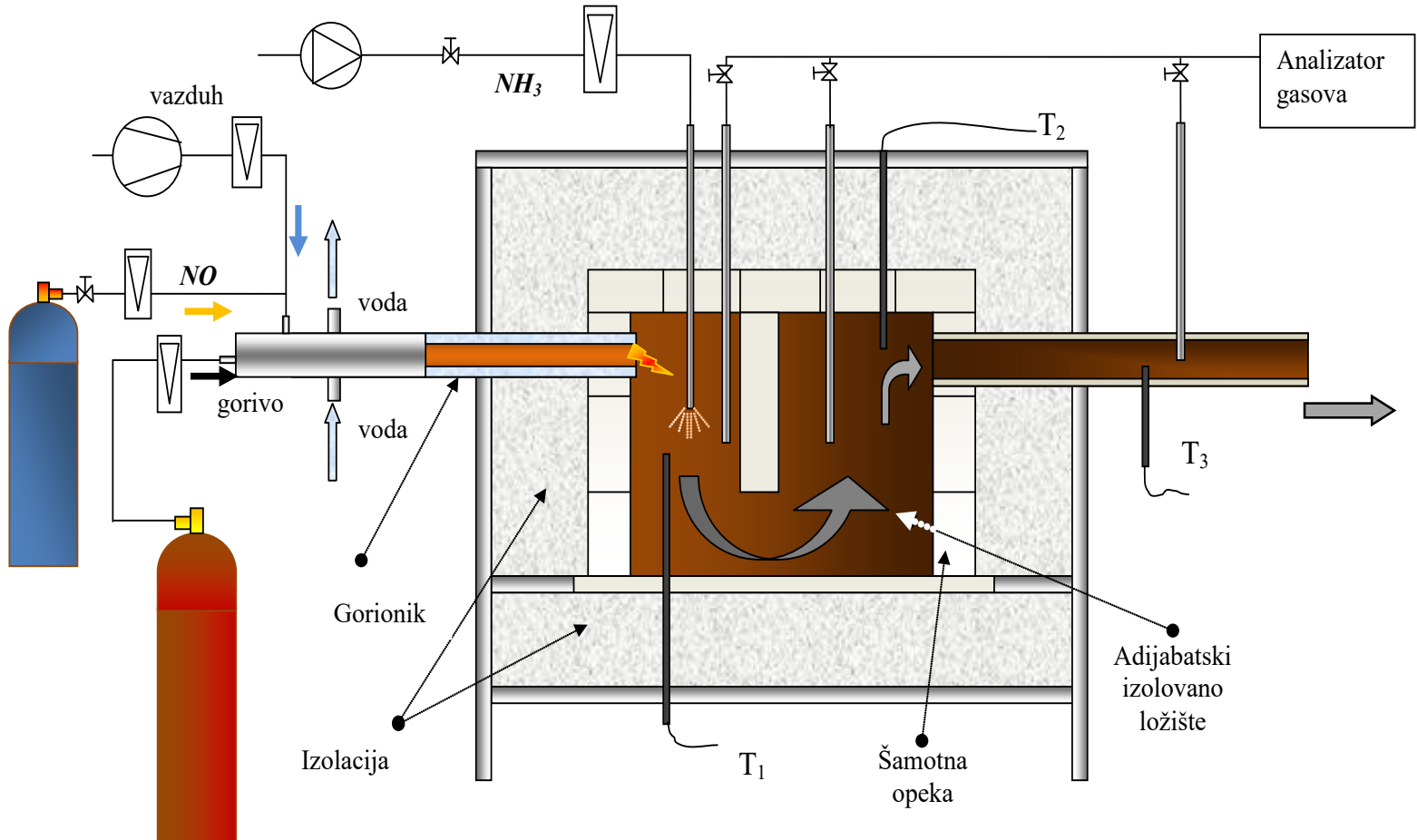

Slika 3. Šema adijabatskog ložišta za simulaciju sagorevanja biomase sa pratećom mernom opremom

Adijabatsko ložište je dimenzija $(120 \times 400 \times 500) \mathrm{mm}$ sa jednom pregradom (omogućava bolje mešanje dimnih gasova), ozidano je šamotnom ciglom i obloženo sa višeslojnom izolacijom ukupne debljine $180 \mathrm{~mm}$. Ložište sa izolacijom je smešteno u limeno kućište. Dobro konstruisan gorionik je ključni element za postizanje zadovoljavajućih performansi sagorevanja. Gorivo-mešavina propanbutana, zajedno sa vazduhom i azot monoksidom, NO, se uvodi centralnom cevi gorionika sa samopaljenjem piezoelektričnim efektom. Gorionik je konstruisan tako da se spreči njegovo pregrevanje uvođenjem centralnog vazduha, koji je ujedno i potreban vazduh za sagorevanje, i anularnim uvođenjem vode za hlađenje vrha gorionika. Vod za vazduh se sastoji od duvaljke za vazduh, varijatora napona, kojim se podešava željeni protok i rotametra-merača protoka. Predviđeno je najjednostavnije rešenje za uvođenje NO - kroz vod za vazduh. Željena količina NO se određuje proračunom, a reguliše ventilom i meri rotametrom. Kako propan butan u svom sastavu ne sadrži azot, a predviđene temperature u ložištu treba da budu takve da ne dolazi do formiranja termičkog NOx-a, ubačeni NO ima ulogu simulacije azot monoksida koji se oslobodi prilikom sagorevanja biomase. Za selektivnu nekatalitičku redukciju SNCR reagens se direktno ubrizgava u komoru za sagorevanje u temperaturskom okviru od $850-950^{\circ} \mathrm{C}$. Potrebno je istaći da SNCR zasnovana na urei ima prednost nad sistemima zasnovanim na amonijaku $\left(\mathrm{NH}_{3}\right)$ zbog veće stabilnosti i netoksičnosti uree, te lakšeg skladištenja i manipulacije. Uz 
to, kapi uree ubrizgane u kotao prodiru dalje, bolje se mešaju sa dimnim gasovima što je posebno važno u velikim postrojenjima. Međutim, urea je skuplja od $\mathrm{NH}_{3}$ i redukcija ureom stvara više $\mathrm{N}_{2} \mathrm{O}$ od sistema baziranih na amonijaku. U planiranom eksperimentu zbog malog kapaciteta ložišta, koristiće se amonijak $\left(\mathrm{NH}_{3}\right)$ kao reagens.

Temperature će se meriti termoparovima $u$ tri tačke, $u$ dve tačke $u$ prvoj i drugoj promaji $u$ ložištu, kao i u izlaznom gasnom kanalu, a na istim mestima vršiće se i analiza dimnih gasova.

\section{PRORAČUN PARAMETARA SAGOREVANJA}

Radno gorivo je tečni naftni gas - smeša propan $\left(\mathrm{C}_{3} \mathrm{H}_{8}\right)$ - butana $\left(\mathrm{C}_{4} \mathrm{H}_{10}\right)$ u odnosu 35:65\%. Na osnovu procentualnog masenog udela svakog od gasova u mešavini dobija se elementarni sastav radnog goriva, tako da je maseni udeo jedina dva zastupljena elementa: $\mathrm{C}=82.41 \%$ i $\mathrm{H}=17.59 \%$.

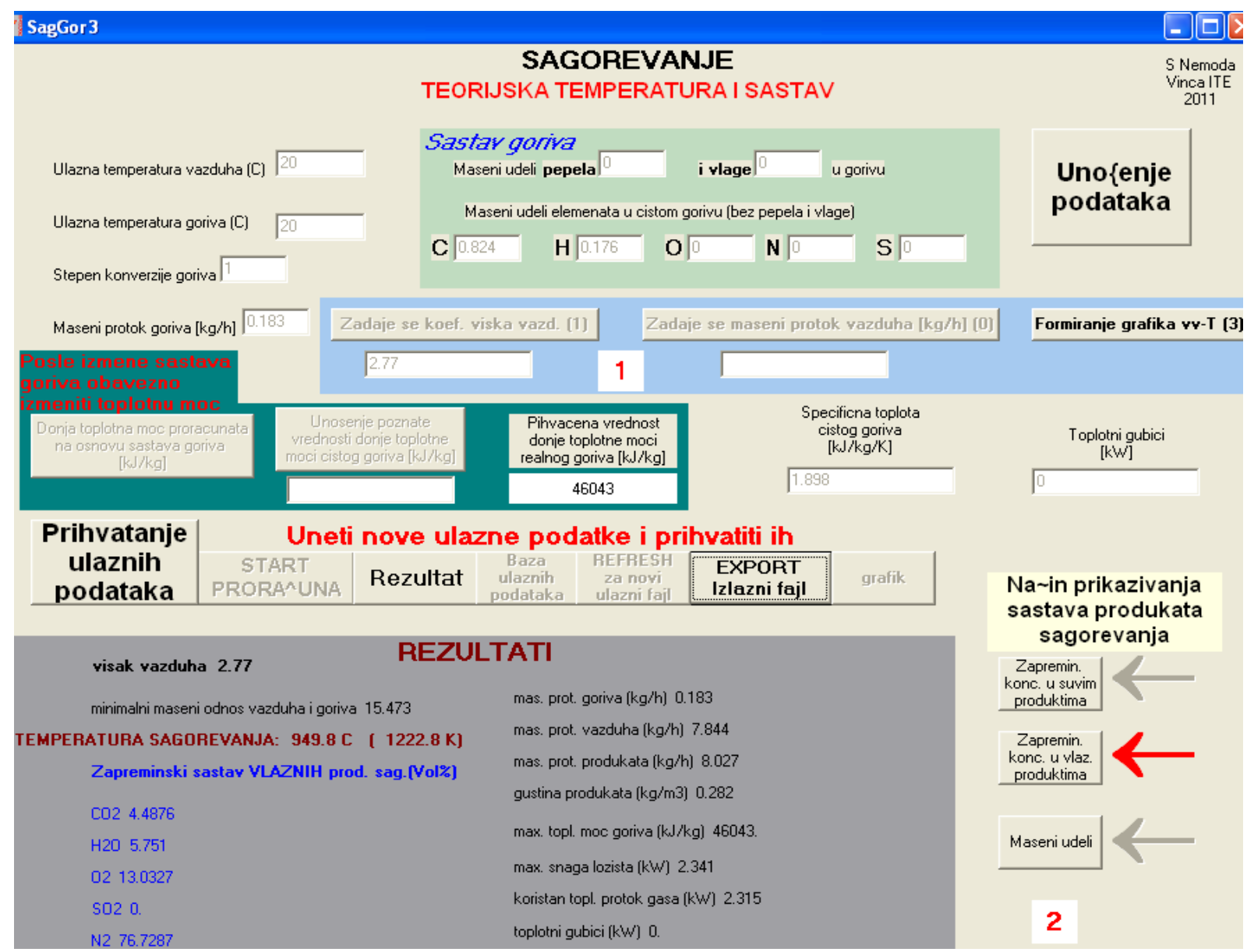

Slika 4. Maska korisničkog računarskog programa za određivanje teoretske temperature sagorevanja i sastava dimnih gasova pri sagorevanju proizvoljnog goriva poznatog elementarnog sastava

Na slici 4 je dat interface programskog paketa za određivanje osnovnih parametara sagorevanja, razvijenog u Laboratoriji za termotehniku i energetiku.

Osnovna funkcija formiranog programskog paketa je brzo i jednostavno određivanje tačne teorijske temperature i sastava gasovitih produkata prilikom idealnog sagorevanja proizvoljnog goriva, baziranog na elementima: $\mathrm{C}, \mathrm{H}, \mathrm{O}, \mathrm{S}$ i N. Pod idealnim sagorevanjem ovde se podrazumeva potpuno sagorevanje bez formiranja $\mathrm{CO}$ i $\mathrm{NO}_{\mathrm{x}}$ komponenata, pri čemu su vazduh i gorivo idealno izmešani i ne uzimaju se u obzir efekti disocijacije. U osnovi se posmatraju adijabatski uslovi sagorevanja, mada treba odmah napomenuti da program predviđa i proračun uticaja neproreagovanosti jednog dela goriva, ukoliko je poznat stepen konverzije goriva, na teorijsku temperaturu reakcije i sastav produkata sagorevanja. Takođe, postoji opcija zadavanja toplotnih gubitaka, čime se dobija podatak o realnoj, neadijabatskoj temperaturi, ukoliko su toplotni gubici poznati. Program pruža i mogućnost određivanja globalnih i materijalnih bilansa u industrijskim ložištima, kao što je maksimalna snaga ložišta, ukoliko 
su poznati maseni protoci goriva i vazduha i maseni protok produkata sagorevanja i njihova gustina, što daje podatak i o zapreminskom protoku produkata sagorevanja.

$\mathrm{Na}$ osnovu elementarnog sastava goriva proračunom za željene adijabatske temperature sagorevanja $(850,900 \mathrm{i} 950){ }^{\circ} \mathrm{C}$ i zadate protoke radnog goriva, navedenim programskim paketom dobijaju se parametri sagorevanja navedeni u tabeli 2 .

Tabela 2. Rezultati proračuna parametara sagorevanja

\begin{tabular}{|c|c|c|c|c|}
\hline Minimal. maseni odnos vazduha i goriva & \multicolumn{4}{|l|}{15.473} \\
\hline max. topl. moć goriva $(\mathrm{kJ} / \mathrm{kg})$ & \multicolumn{4}{|l|}{46043} \\
\hline $\begin{array}{l}\text { TEMPERATURA SAGOREVANJA: } \\
\text { višak vazduha }\end{array}$ & \multicolumn{4}{|c|}{$\begin{array}{l}851^{\circ} \mathrm{C} \quad(1124.4 \mathrm{~K}) \\
3.15\end{array}$} \\
\hline Zapreminski sastav prod. sag.(Vol\%) & \\
\hline $\mathrm{CO}_{2}$ & \multicolumn{4}{|l|}{3.9599} \\
\hline $\mathrm{H}_{2} \mathrm{O}$ & \multicolumn{4}{|l|}{5.0749} \\
\hline $\mathrm{O}_{2}$ & \multicolumn{4}{|l|}{13.9694} \\
\hline $\mathrm{SO}_{2}$ & \multirow{2}{*}{\multicolumn{4}{|c|}{$\begin{array}{l}0.0 \\
769958\end{array}$}} \\
\hline $\mathrm{N}_{2}$ & & & & \\
\hline gustina produkata $\left(\mathrm{kg} / \mathrm{m}^{3}\right)$ & \multicolumn{4}{|l|}{0.307} \\
\hline Pokazivanje na rotametru $(\mathrm{l} / \mathrm{h})$ & 70 & 50 & 30 & 20 \\
\hline mas. protok goriva $(\mathrm{kg} / \mathrm{h})$ & 0.183 & 0.165 & 0.113 & 0.083 \\
\hline mas. protok vazduha $(\mathrm{kg} / \mathrm{h})$ & 8.92 & 8.042 & 5.508 & 4.045 \\
\hline mas. protok produkata $(\mathrm{kg} / \mathrm{h})$ & 9.103 & 8.207 & 5.621 & 4.128 \\
\hline max. snaga ložišta $(\mathrm{kW})$ & 2.341 & 2.11 & 1.445 & 1.062 \\
\hline koristan topl. protok gasa $(\mathrm{kW})$ & 2.321 & 2.093 & 1.433 & 1.053 \\
\hline $\begin{array}{l}\text { TEMPERATURA SAGOREVANJA: } \\
\text { višak vazduha }\end{array}$ & \multicolumn{4}{|c|}{$\begin{array}{l}903^{\circ} \mathrm{C}(1176 \mathrm{~K}) \\
2.94\end{array}$} \\
\hline Zapreminski sastav prod. sag.(Vol\%) & & & & \\
\hline $\mathrm{CO}_{2}$ & 4.2351 & & & \\
\hline $\mathrm{H}_{2} \mathrm{O}$ & \multicolumn{4}{|l|}{5.4275} \\
\hline $\mathrm{O}_{2}$ & \multicolumn{4}{|l|}{13.4808} \\
\hline $\mathrm{SO}_{2}$ & \multirow{2}{*}{\multicolumn{4}{|c|}{0.0}} \\
\hline $\mathrm{N}_{2}$ & \multirow{2}{*}{\multicolumn{4}{|c|}{76.8565}} \\
\hline gustina produkata $\left(\mathrm{kg} / \mathrm{m}^{3}\right)$ & & & & \\
\hline Pokazivanje na rotametru $(1 / \mathrm{h})$ & 70 & 50 & 30 & 20 \\
\hline mas. protok goriva $(\mathrm{kg} / \mathrm{h})$ & 0.183 & 0.165 & 0.113 & 0.083 \\
\hline mas. protok vazduha $(\mathrm{kg} / \mathrm{h})$ & 8.325 & 7.506 & 5.141 & 3.776 \\
\hline mas. protok produkata $(\mathrm{kg} / \mathrm{h})$ & 8.508 & 7.671 & 5.254 & 3.859 \\
\hline max. snaga ložišta $(\mathrm{kW})$ & 2.341 & 2.11 & 1.445 & 1.062 \\
\hline koristan topl. protok gasa $(\mathrm{kW})$ & 2.318 & 2.09 & 1.431 & 1.051 \\
\hline $\begin{array}{l}\text { TEMPERATURA SAGOREVANJA: } \\
\text { višak vazduha }\end{array}$ & \multicolumn{4}{|c|}{$\begin{array}{l}950^{\circ} \mathrm{C}(1223 \mathrm{~K}) \\
2.77\end{array}$} \\
\hline Zapreminski sastav prod. sag.(Vol\%) & & & & \\
\hline $\mathrm{CO}_{2}$ & \multicolumn{4}{|l|}{4.4876} \\
\hline $\mathrm{H}_{2} \mathrm{O}$ & \multicolumn{4}{|l|}{5.751} \\
\hline $\mathrm{O}_{2}$ & \multicolumn{4}{|l|}{13.0327} \\
\hline $\mathrm{SO}_{2}$ & \multirow{2}{*}{\multicolumn{4}{|c|}{$\begin{array}{l}0 . \\
76.7287\end{array}$}} \\
\hline $\mathrm{N}_{2}$ & & & & \\
\hline gustina produkata $\left(\mathrm{kg} / \mathrm{m}^{3}\right)$ & \multicolumn{4}{|l|}{0.282} \\
\hline Pokazivanje na rotametru $(\mathrm{l} / \mathrm{h})$ & 70 & 50 & 30 & 20 \\
\hline mas. protok goriva $(\mathrm{kg} / \mathrm{h})$ & 0.183 & 0.165 & 0.113 & 0.083 \\
\hline mas. protok vazduha $(\mathrm{kg} / \mathrm{h})$ & 7.844 & 7.072 & 4.843 & 3.557 \\
\hline mas. protok produkata $(\mathrm{kg} / \mathrm{h})$ & 8.027 & 7.237 & 4.956 & 3.64 \\
\hline max. snaga ložišta $(\mathrm{kW})$ & 2.341 & 2.11 & 1.445 & 1.062 \\
\hline koristan topl. protok gasa $(\mathrm{kW})$ & 2.315 & 2.087 & 1.429 & 1.05 \\
\hline
\end{tabular}




\section{ODREĐIVANJE PROTOKA NO KOJI SE DODAJE PRI SAGOREVANJU}

Da bi se u produktima sagorevanja gasnom analizom dobilo 500 ppm, koliko se očekuje pri sagorevanja agrarne biomase, bogate azotom, u produktima sagorevanja potrebno je dodati NO u količini datoj u tabeli 3 .

Tabela 3. Proračun potrebne količine azot monoksida za detekciju 500ppm u ložištu

\begin{tabular}{|c|c|c|c|c|c|c|}
\hline \multirow{2}{*}{$851^{\circ} \mathrm{C}$} & maseni protok produkata & $\overline{(2 \mathrm{~kg} / \mathrm{h})}$ & 9.1 & 8.2 & $\overline{5.6}$ & 4.1 \\
\hline & maseni protok vazduha & $(1 / \mathrm{h})$ & 7402.5 & 6674 & 4571 & 3356.8 \\
\hline \multirow{3}{*}{$500 \mathrm{ppm}$} & \multirow{3}{*}{ NO } & $(\mathrm{kg} / \mathrm{h})$ & 0.0045 & 0.0041 & 0.0028 & 0.0021 \\
\hline & & $(\mathrm{g} / \mathrm{h})$ & 4.55 & 4.11 & 2.81 & 2.06 \\
\hline & & $(1 / h)$ & 3.65 & 3.29 & 2.25 & 1.65 \\
\hline \multirow{2}{*}{$903^{\circ} \mathrm{C}$} & maseni protok produkata & $(\mathrm{kg} / \mathrm{h})$ & 8.5 & 7.7 & 5.2 & 3.8 \\
\hline & maseni protok vazduha & $(1 / h)$ & 6908.7 & 6229 & 4266 & 3134 \\
\hline \multirow{3}{*}{$500 \mathrm{ppm}$} & \multirow{3}{*}{ NO } & $(\mathrm{kg} / \mathrm{h})$ & 0.0042 & 0.0038 & 0.0026 & 0.0019 \\
\hline & & $(\mathrm{g} / \mathrm{h})$ & 4.26 & 3.83 & 2.63 & 1.93 \\
\hline & & $(1 / h)$ & 3.40 & 3.07 & 2.10 & 1.5 \\
\hline \multirow{2}{*}{$950^{\circ} \mathrm{C}$} & maseni protok produkata & $(\mathrm{kg} / \mathrm{h})$ & 8 & 7.2 & 4.96 & 3.64 \\
\hline & maseni protok vazduha & $(1 / h)$ & 6509.5 & 5868.9 & 4019.1 & 2951.9 \\
\hline \multirow{3}{*}{$500 \mathrm{ppm}$} & \multirow{3}{*}{ NO } & $(\mathrm{kg} / \mathrm{h})$ & 0.0040 & 0.0036 & 0.0025 & 0.0018 \\
\hline & & $(\mathrm{g} / \mathrm{h})$ & 4.01 & 3.62 & 2.48 & 1.82 \\
\hline & & $(1 / h)$ & 3.21 & 2.9 & 1.98 & 1.46 \\
\hline
\end{tabular}

\section{ZAKLJUČAK}

Poznavanje emisije i procesa redukcije NOx-a je potrebno za razvoj i unapređenje tehnologija sagorevanja biomase pa stoga i na pravilan izbor mera za denitrifikaciju. Dominantan uticaj na emisiju azota pri sagoravanju goriva tipa biomase ima azot vezan $u$ gorivu, $s$ obzirom da je emisija termičkog NOx-a zanemarljiva na temperaturama sagorevanja od $850-950^{\circ} \mathrm{C}$. U pogledu emisije azotnih jedinjenja posebno je kritična poljoprivredna i to pre svega agrarna biomasa zbog izraženog sadržaja azota u njenom sastavu. U radu je opisana eksperimentalna aparatura za simulaciju sagorevanja agrarne biomase, u navedenom temperaturskom opsegu, kojom će sa na jednostavan i efikasan način optimizirati proces redukcije azotnih oksida koji se emituju u procesu sagorevanja. Dati su i izračunati parametri sagorevanja predmetnog goriva i na taj način utvrđene vrednosti za definisanje kako samog procesa tako i merne opreme koja će se koristiti za akviziciju procesa denitrifikacije metodom selektivne nekatalitičke redukcije. Planom za naredna istraživanja opisana laboratorijska eksperimentalna aparatura dopuniće se hladnjakom dimnih gasova sa katalizatorom u cilju ispitivanja druge najzastupljenije metode sekundarne denitrifikacije - SCR - selektivne katalitičke redukcije.

\section{ZAHVALNOST}

Autori žele da izraze zahvalnost Ministarstvu obrazovanja, nauke i tehnološkog razvoja Republike Srbije za finansiranje projekata: "Unapređenje industrijskog postrojenja sa fluidizovanim slojem u okviru razvoja tehnologije za energetski efikasno i ekološki opravdano sagorevanje različitih otpadnih materija u fluidizacionom ložištu" (TR33042), i "Razvoj i unapređenje tehnologije za efikasno korišćenje energije nekoliko oblika poljoprivredne i šumske biomase na ekološki prihvatljiv način, uz mogućnost kogeneracije" (III 42011). 


\section{LITERATURA}

[1] Mladenović, M.R., D.V. Dakić, S.Đ. Nemoda, M.J. Paprika, M.S. Komatina, B.S. Repić , A.M. Erić, The combustion of biomass - the impact of its types and combustion technologies on the emission of nitrogen oxide, Hemijska industrija, 70 (2016), 3, 287-298

[2] Obernberger, I., T. Brunner, G. Bärnthaler, Chemical properties of solid biofuelssignificance and impact, Biomass and Bioenergy, 30 (2006), 973-982.

[3] Khan, A., W.De Jong, P. J. Jansens, H. Spliethoff, Biomass combustion in fluidized bed boilers: Potential problems and remedies, Fuel Processing Technology 90 (2009) 21-50.

[4] EPA Technical Bullletein, Nitrogen Oxides (NOx), Why and How They Are Controlled, EPA456/F-99-006R, November 1999, http://www.epa.gov/ttncatc1/dir1/fnoxdoc.pdf

[5] Leckner, B., Karlsson, M., Gaseous emissions from circulating fluidized bed combustion of wood, Biomass Bioenergy 4 (1993), 379-389.

[6] Leckner, C., S. Chyang, F. P. Qian, Y. C. Lin, S. H.Yang, $\mathrm{NO}$ and $\mathrm{N}_{2} \mathrm{O}$ emission characteristics from a pilot scale vortexing fluidized bed combustor firing different fuels, Energy Fuels 22 (2008), 1004-1011.

[7] Mladenović, M. , Paprika, M. , Marinković, A., Mere denitrifikacije pri sagorevanju biomase, Zbornik radova na CD-ROM-u, /29. Međunarodni kongres o procesnoj industriji-Procesing '16, 2. i 3. jun 2016, Beograd, Sava centar, organizator Savez mašinskih i elektrotehničkih inženjera i tehničara Srbije (SMEITS), Društvo za procesnu tehniku; urednici Miroslav Stanojević, Aleksandar Jovović, str 173-187.

[8] Mladenović, M. R. , Dakić, D. V., Nemoda, S. Đ., Paprika, M. J., Marinković, A. D., Erić, A. M., Đurović, D. M., Repić, B. S., Combustion of hazelnut shells in a fluidized bed, Proceedings of International Conference „Power Plants 2016“, 23-26 November 2016, Zlatibor, Serbia, ISBN 978-86-7877-027-2

[9] Demirbas, A., Combustion characteristics of different biomass fuels, Progress in Energy and Combustion Science, 30 (2004), 2, 219-230

[10] Uredba o graničnim vrednostima emisija zagađujućih materija u vazduh iz postrojenja za sagorevanje,"Sl. glasnik RS", br. 6/2016 